\title{
Serum lipid and lipoprotein levels of middle-aged and elderly Chinese men and women in Shandong Province
}

\author{
Meijian Wang ${ }^{1}$, Xinguo Hou², Wenchao Hu' ${ }^{1}$ Li Chen ${ }^{2}$ and Shihong Chen ${ }^{3 *}$
}

\begin{abstract}
Background: Cardiovascular and cerebrovascular diseases have become leading causes of death in China as the economy develop and lifestyles change. This study aimed to estimate the relationship of the age, gender, and glucose metabolism with the serum lipid and lipoprotein levels of middle-aged and elderly Chinese men and women in Shandong Province.
\end{abstract}

Methods: We conducted a cross-sectional study in Shandong Province that included 10,028 adults aged $\geq 40$ years. Fasting serum total, low-density lipoprotein (LDL), high-density lipoprotein (HDL) cholesterol and triglycerides were measured by standard methods.

Results: The estimates of total, $L D L$, and HDL cholesterol and triglycerides were as follows: $5.35,3.18,1.51$, and 1.34 $\mathrm{mmol} / \mathrm{L}$ in the middle-aged and elderly Chinese adult population; $5.14,3.08,1.42$, and $1.33 \mathrm{mmol} / \mathrm{L}$ in male subjects; $5.46,3.24,1.56$, and $1.34 \mathrm{mmol} / \mathrm{L}$ in females; $5.27,3.11,1.54$, and $1.24 \mathrm{mmol} / \mathrm{L}$ in the normal glucose tolerance population, $5.49,3.27,1.50$, and $1.41 \mathrm{mmol} / \mathrm{L}$ in the population with pre-diabetes, and $5.39,3.23,1.43$, and 1.58 $\mathrm{mmol} / \mathrm{L}$ in the population with diabetes, respectively. Moreover, 36.92 and $19.10 \%$ of the adults had borderline-high and high total cholesterol. The population estimates for borderline-high, high LDL and low HDL cholesterol levels were 25.24, 13.39, and 5.64\%, respectively. Meanwhile, borderline high and high triglyceride levels accounted for 16.7 and $17.47 \%$ of the population, respectively.

Conclusions: Serum total and LDL cholesterol levels were high in the $\geq 40$ years old population of Shandong Province. Age, gender, glucose metabolism status, body mass index (BMI) and glycosylated hemoglobin (HbA1c) can affect serum lipid and lipoprotein levels.

Keywords: Shandong Province, Cross-sectional study, Lipids, Lipoproteins

\section{Background}

With the economic developments and adverse changes in lifestyle (such as a decreased physical activity and high-calorie food intake), cardiovascular and cerebrovascular diseases have become the important cause of death in China [1, 2]. $42.8 \%$ of deaths in adults aged $\geq 40$ years were estimated to be attributable to heart disease and stroke in 1991-2000 in a Chinese national prospective cohort study [2]. Elevated serum lipids are one of the most important modifiable risk factors for cardiovascular

\footnotetext{
* Correspondence: chenshihong26@163.com

${ }^{3}$ Department of Endocrinology, The Second Hospital of Shandong University, 247 Beiyuan Street, Ji'nan, Shandong 250033, People's Republic of China Full list of author information is available at the end of the article
}

and cerebrovascular diseases in Western [3-5] and Asian $[6,7]$ populations. We try to estimate the relationship between age, gender, status of glucose metabolism, and serum lipids and lipoproteins among the Chinese men and women aged $\geq 40$ years of Shandong Province.

\section{Methods \\ Study population}

In 2012, we conducted an epidemiological survey of type 2 diabetes in Shandong Province. We chose several communities in the cities of Jinan and Jining in Shandong Province. A total of 10,028 individuals participated in the study. After excluding 273 persons with missing demographic information and lipid data, we covered

(c) The Author(s). 2019 Open Access This article is distributed under the terms of the Creative Commons Attribution 4.0 International License (http://creativecommons.org/licenses/by/4.0/), which permits unrestricted use, distribution, and 
9755 adults in the final analysis (3313 men and 6442 women). The present work was one part of the baseline survey from the REACTION study that investigated the association of diabetes and cancer, conducted among 259,657 adults aged $\geq 40$ years in 25 communities across mainland China, from 2011 to 2012 [8-11].

The ethics committee of Qilu Hospital of Shandong University approved the study. Written informed consent was obtained from each participant before data collection.

\section{Data collection}

Data collection was conducted at local community hospital or community medical center in the participants' residential area. During the clinic visits, trained research staff collected information on demographic characteristics, personal and family medical history, medication history, and lifestyle risk factors according to a standard questionnaire [12]. It also included questions about the diagnosis and treatment of dyslipidemia. Cigarette smoking, alcohol drinking, and physical activities were also recorded. Blood pressure, heart rate, height, body weight, and waist circumference were measured by standard methods [13]. Body mass index (BMI) was calculated as weight in kilograms divided by the square of height in meters. Waist-hip ratio (WHR) was calculated as waist circumference in centimeter divided by the hip circumference in centimeter.
Blood samples were drawn by venipuncture after at least $8 \mathrm{~h}$ of overnight fasting to measure serum total, low-density lipoprotein (LDL), and high-density lipoprotein (HDL) cholesterol, triglycerides, fasting plasma glucose (FPG), fasting plasma insulin (FINS), glycosylated hemoglobin $(\mathrm{HbAlc})$, creatinine $(\mathrm{Cr})$, alanine aminotransferase (ALT), and aspartate aminotransferase (AST). Homeostasis model assessment insulin resistance (HOMA-IR) was calculated as FPG multiplied by FINS divided by 22.5. Blood specimens were processed at local medical center and sent to the central laboratories.

Diagnosis of diabetes is according to ADA [14]: FPG $\geq 7.0 \mathrm{~mol} / \mathrm{L}, 2 \mathrm{hPG} \geq 11.1 \mathrm{mmol} / \mathrm{L}$, also include those have been diagnosed diabetes and began to therapy. Pre-diabetes include: impaired fasting glucose (IFG), impaired glucose tolerance (IGT) and IFG accompanied with IGT. IFG defines as FPG $5.6-6.9 \mathrm{mmol} / \mathrm{L}$ and $2 \mathrm{hPG}<7.8 \mathrm{mmol} / \mathrm{L}$. IGT defines as FPG $<7.0 \mathrm{mmol} / \mathrm{L}$ and $2 \mathrm{hPG} 7.8-11.0 \mathrm{mmol} / \mathrm{L}$.

Mean levels of total, LDL, and HDL cholesterol and triglycerides were estimated for the overall population by gender and status of glucose metabolism. Moreover, age-specific mean levels were calculated for men and women. Serum lipids and lipoprotein levels were classified on the basis of the Third Report of the Expert Panel on Detection, Evaluation, and Treatment of High Blood Cholesterol in Adults [13]. The prevalence estimates of total, LDL, and HDL cholesterol categories

Table 1 Demographic and clinical characteristics of study participants in Shandong Province

\begin{tabular}{|c|c|c|c|c|}
\hline & $\begin{array}{l}\text { Overall } \\
N=9755\end{array}$ & $\begin{array}{l}\text { Men } \\
N=3313\end{array}$ & $\begin{array}{l}\text { Women } \\
N=6442\end{array}$ & $P$ values \\
\hline Age, y & $58.58 \pm 9.81$ & $60.15 \pm 9.98$ & $57.78 \pm 9.62$ & $<0.01$ \\
\hline $\mathrm{BMl}, \mathrm{kg} / \mathrm{m}^{2}$ & $26.25 \pm 3.48$ & $26.48 \pm 3.25$ & $26.13 \pm 3.59$ & $<0.01$ \\
\hline Systolic BP, mm Hg & $139.55 \pm 21.32$ & $142.06 \pm 20.26$ & $138.26 \pm 21.73$ & $<0.01$ \\
\hline Diastolic BP, mm Hg & $80.15 \pm 14.34$ & $83.15 \pm 18.63$ & $78.60 \pm 11.22$ & $<0.01$ \\
\hline Waist circumference, $\mathrm{cm}$ & $86.86 \pm 10.09$ & $90.54 \pm 9.40$ & $84.98 \pm 9.92$ & $<0.01$ \\
\hline Waist-hip ratio & $0.86 \pm 0.06$ & $0.89 \pm 0.06$ & $0.84 \pm 0.06$ & $<0.01$ \\
\hline Glycosylated hemoglobin, \% & $6.25 \pm 1.25$ & $6.32 \pm 1.35$ & $6.21 \pm 1.19$ & $<0.01$ \\
\hline Fasting glucose, $\mathrm{mmol} / \mathrm{L}$ & $6.16 \pm 1.90$ & $6.40 \pm 2.10$ & $6.03 \pm 1.78$ & $<0.01$ \\
\hline Fasting plasma insulin, ulU/ml & $9.43 \pm 6.63$ & $8.88 \pm 6.34$ & $9.71 \pm 6.76$ & $<0.01$ \\
\hline HOMA-IR & $2.67 \pm 2.72$ & $2.59 \pm 2.45$ & $2.71 \pm 2.84$ & $<0.05$ \\
\hline Creatinine, ummol/L & $65.19 \pm 13.78$ & $74.41 \pm 16.05$ & $60.45 \pm 9.43$ & $<0.01$ \\
\hline Alanine aminotransferase, $\mathrm{U} / \mathrm{L}$ & $11.00(8.00-15.00)$ & $12.00(9.00-17.00)$ & 10.00(7.00-14.00) & $<0.01$ \\
\hline Aspartate aminotransferase, $\mathrm{U} / \mathrm{L}$ & $18.00(16.00-22.00)$ & $19.00(16.00-23.00)$ & $18.00(16.00-21.00)$ & $<0.01$ \\
\hline Total cholesterol, mmol/L & $5.35 \pm 1.05$ & $5.15 \pm 0.98$ & $5.46 \pm 1.07$ & $<0.01$ \\
\hline LDL cholesterol, mmol/L & $3.18 \pm 0.86$ & $3.08 \pm 0.81$ & $3.24 \pm 0.88$ & $<0.01$ \\
\hline HDL cholesterol, mmol/L & $1.51 \pm 0.38$ & $1.42 \pm 0.38$ & $1.56 \pm 0.37$ & $<0.01$ \\
\hline Triglycerides, mmol/L & $1.34(0.95-1.92)$ & $1.33(0.96-1.91)$ & $1.34(0.95-1.92)$ & 0.41 \\
\hline
\end{tabular}

Mean values (95\% confidence interval $[C I])$ are shown. $B M I$ body mass index, $B P$ blood pressure, $L D L$ low-density lipoprotein, $H D L$ high-density lipoprotein, HOMA-IR homeostasis model assessment insulin resistance

$P$ values between men and women 
were calculated for the total population and by gender with the use of the direct method according to the population distribution in China in 2008 [15].

\section{Statistical analysis}

All statistical analyses were conducted using the SPSS 19.0. Normally distributed data were expressed as mean \pm standard deviation $\left({ }^{-} x \pm s\right)$. None-normally distribution data were expressed as median and quartile. All $P$ values were two-tailed and not adjusted for multiple testing. The differences of characteristics between men and women were compared with unpaired $t$-test or chi-square tests. One-way ANOVA was used to compare the differences of characteristics between different aged groups. Age-specific prevalence of dyslipidemia was also calculated.

\section{Results}

Table 1 shows the demographic and clinical characteristics of the study participants categorized into men, women, and overall population.

\section{Mean lipid and lipoprotein levels}

The mean levels of total, LDL, and HDL cholesterol and triglycerides were $5.35,3.18,1.51$, and $1.34 \mathrm{mmol} / \mathrm{L}$, respectively, in the overall Shandong Province population

Table 2 Mean (95\% Cl) Level of Serum Total, LDL, HDL Cholesterol, and Triglycerides in Shandong Adults Aged $\geq 40$ years, 2012

\begin{tabular}{|c|c|c|c|c|}
\hline & \multicolumn{3}{|c|}{ Serum Cholesterol, mmol/L } & \multirow{2}{*}{$\begin{array}{l}\text { Serum Triglycerides } \\
\mathrm{mmol} / \mathrm{L}\end{array}$} \\
\hline & Total & $\mathrm{LDL}$ & $\mathrm{HDL}$ & \\
\hline \multicolumn{5}{|l|}{ Sex- and age-specific } \\
\hline \multicolumn{5}{|l|}{ Men, age, y } \\
\hline $40-44$ & $4.99 \pm 0.93$ & $2.90 \pm 0.77$ & $1.40 \pm 0.31$ & $1.38(1.02-2.18)$ \\
\hline $45-49$ & $5.20 \pm 0.97$ & $3.00 \pm 0.79$ & $1.41 \pm 0.40$ & $1.55(1.03-2.29)$ \\
\hline $50-54$ & $5.08 \pm 0.96$ & $3.01 \pm 0.73$ & $1.43 \pm 0.36$ & $1.34(0.93-1.92)$ \\
\hline $55-59$ & $5.19 \pm 1.04$ & $3.12 \pm 0.85$ & $1.42 \pm 0.39$ & $1.38(0.99-2.07)$ \\
\hline $60-64$ & $5.19 \pm 0.98$ & $3.13 \pm 0.83$ & $1.40 \pm 0.36$ & 1.34(1.00-1.86) \\
\hline $65-69$ & $5.19 \pm 0.90$ & $3.12 \pm 0.81$ & $1.42 \pm 0.35$ & $1.26(0.92-1.75)$ \\
\hline$\geq 70$ & $5.11 \pm 0.98$ & $3.10 \pm 0.80$ & $1.44 \pm 0.40$ & $1.24(0.91-1.75)$ \\
\hline$P$ values for linear trend & 0.29 & $<0.05$ & 0.30 & $<0.05$ \\
\hline \multicolumn{5}{|l|}{ Women, age, y } \\
\hline $40-44$ & $4.74 \pm 0.90$ & $2.73 \pm 0.73$ & $1.59 \pm 0.33$ & $1.00(0.75-1.39)$ \\
\hline $45-49$ & $5.05 \pm 1.05$ & $2.94 \pm 0.85$ & $1.61 \pm 0.37$ & $1.06(0.76-1.59)$ \\
\hline $50-54$ & $5.42 \pm 1.06$ & $3.20 \pm 0.87$ & $1.61 \pm 0.36$ & $1.26(0.88-1.75)$ \\
\hline $55-59$ & $5.54 \pm 1.00$ & $3.31 \pm 0.82$ & $1.56 \pm 0.39$ & $1.41(1.02-2.05)$ \\
\hline $60-64$ & $5.72 \pm 1.03$ & $3.40 \pm 0.88$ & $1.51 \pm 0.34$ & $1.52(1.07-2.15)$ \\
\hline $65-69$ & $5.67 \pm 0.99$ & $3.42 \pm 0.83$ & $1.51 \pm 0.36$ & $1.46(1.11-2.05)$ \\
\hline$\geq 70$ & $5.75 \pm 1.07$ & $3.44 \pm 0.92$ & $1.53 \pm 0.40$ & $1.51(1.11-2.10)$ \\
\hline$P$ values for linear trend & $<0.01$ & $<0.01$ & $<0.05$ & $<0.01$ \\
\hline \multicolumn{5}{|c|}{ Status of glucose metabolism } \\
\hline NGT & $5.27 \pm 1.01$ & $3.11 \pm 0.83$ & $1.54 \pm 0.38$ & $1.24(0.89-1.76)$ \\
\hline Prediabetes & $5.49 \pm 1.07$ & $3.27 \pm 0.88$ & $1.50 \pm 0.35$ & $1.41(1.00-1.98)$ \\
\hline Diabetes & $5.39 \pm 1.09$ & $3.23 \pm 0.90$ & $1.43 \pm 0.39$ & $1.58(1.11-2.27)$ \\
\hline$P$ values for difference & $<0.01$ & $<0.01$ & $<0.01$ & $<0.01$ \\
\hline \multicolumn{5}{|l|}{ Blood pressure } \\
\hline NBP & $5.06 \pm 1.13$ & $3.05 \pm 0.87$ & $1.60 \pm 0.43$ & $1.10(0.80-1.58)$ \\
\hline Prehypertension & $5.30 \pm 1.00$ & $3.11 \pm 0.84$ & $1.53 \pm 0.35$ & $1.22(0.88-1.74)$ \\
\hline Hypertension & $5.48 \pm 1.01$ & $3.26 \pm 0.85$ & $1.47 \pm 0.34$ & $1.36(1.05-2.04)$ \\
\hline$P$ values for difference & $<0.01$ & $<0.05$ & $<0.01$ & $<0.05$ \\
\hline
\end{tabular}

LDL low-density lipoprotein, HDL high-density lipoprotein, NGT normal glucose tolerance, Prediabetes contains: (1) IFG, impaired fasting glucose; (2) IGT, impaired glucose tolerance; (3) IFG accompany with IGT. NBP, normal blood pressure, systolic blood pressure $<120 \mathrm{mmHg}$ and diastolic blood pressure $<80 \mathrm{mmHg}$ $(1 \mathrm{mmHg}=0.133 \mathrm{kPa}$ ); Prehypertension, systolic blood pressure $120-139 \mathrm{mmHg}$ and/or diastolic blood pressure $80-89 \mathrm{mmHg}$; Hypertension, systolic blood pressure $\geq 140 \mathrm{mmHg}$ or diastolic blood pressure $\geq 90 \mathrm{mmHg}$ 
aged $\geq 40$ years (Table 1 ). Generally, these mean levels were slightly higher in women than in men. In addition, the mean levels of total and LDL cholesterol and triglycerides increased with age until 60-64 years, and the mean levels of total cholesterol and triglycerides subsequently decreased (Table 2). Overall, total and LDL cholesterol levels increased continuously over the entire age range in women. Serum total, LDL, and HDL cholesterol and triglycerides levels were linearly correlated with blood pressure. Serum total, and LDL cholesterol levels in normal glucose tolerance (NGT) group, pre-diabetic group, and diabetic group increased first and then decreased, while HDL cholesterol level decreased gradually, and triglycerides level increased gradually (Table 2).

\section{Prevalence of dyslipidemia}

The prevalence of borderline-high $(5.18-6.21 \mathrm{mmol} / \mathrm{L})$ and high total cholesterol levels $(\geq 6.22 \mathrm{mmol} / \mathrm{L})$ was 36.92 and $19.10 \%$, respectively (Table 3 ), and increased with age in both women and men (Fig.1). Meanwhile, the prevalence of borderline-high $(3.37-4.13 \mathrm{mmol} / \mathrm{L})$ and high LDL cholesterol $(\geq 4.14 \mathrm{mmol} / \mathrm{L})$ was 25.24 and $13.39 \%$, respectively. The prevalence of borderline-high $(1.70-2.25 \mathrm{mmol} / \mathrm{L})$ and high triglycerides $(\geq 2.26 \mathrm{mmol} /$ L) was 16.07 and $17.47 \%$, respectively. The prevalence of low HDL cholesterol $(<1.04 \mathrm{mmol} / \mathrm{L})$ was $5.64 \%$ in the overall adult Shandong population aged $\geq 40$ years and increased with age in women (Fig.2).

\section{The correlation of total, LDL, and HDL cholesterol and triglycerides with other clinical characteristics}

Simple linear regression analyses showed that age, gender, status of glucose metabolism, BMI, and $\mathrm{HbA} 1 \mathrm{c}$ were correlated with total, LDL, and HDL cholesterol and triglycerides (Table 4). Multiple linear regression analyses showed that a) only age, gender, BMI, HbA1c

Table 3 Prevalence of Dyslipidemia

\begin{tabular}{|c|c|c|c|}
\hline & \multicolumn{3}{|c|}{ Prevalence, \% } \\
\hline & Overall & Men & Women \\
\hline \multicolumn{4}{|c|}{ Serum total cholesterol, $\mathrm{mmol} / \mathrm{L}$} \\
\hline $5.18-6.21$ & 36.92 & 35.07 & 37.88 \\
\hline$\geq 6.22^{\mathrm{a}}$ & 19.10 & 13.40 & 22.03 \\
\hline \multicolumn{4}{|c|}{ Serum LDL cholesterol, mmol/L } \\
\hline $3.37-4.13$ & 25.24 & 23.03 & 26.37 \\
\hline$\geq 4.14^{\mathrm{a}}$ & 13.39 & 10.62 & 14.81 \\
\hline \multicolumn{4}{|c|}{ Serum Triglycerides, mmol/L } \\
\hline $1.70-2.25$ & 16.07 & 16.12 & 16.05 \\
\hline$\geq 2.26^{\mathrm{a}}$ & 17.47 & 17.51 & 17.45 \\
\hline \multicolumn{4}{|c|}{ Serum HDL cholesterol, mmol/L } \\
\hline$\leq 1.04$ & 5.64 & 10.26 & 3.26 \\
\hline
\end{tabular}

were associated with total lipoprotein; b) only BMI, and HbA1c were associated with triglycerides; c) only gender, status of glucose metabolism, BMI, and $\mathrm{HbA1c}$ were associated with HDL cholesterol; and d) age, gender, status of glucose metabolism, BMI, and HbA1c still were associated with LDL (Table 4).

\section{Discussion}

Our study shows that mean levels of total and LDL cholesterol and triglycerides are considerably higher than the previous report in the general Chinese adult population [16-19]. Moreover, $56.02 \%$ of the Shandong general population aged $\geq 40$ years have a borderline-high or high total cholesterol level, $38.63 \%$ have a borderline-high or high LDL cholesterol level, and $33.54 \%$ have a borderline-high or high triglycerides level.

Furthermore, glucose metabolism disorder leads to dyslipidemia. The total and LDL cholesterol and triglyceride levels increased by $4.17 \%(0.22), 5.14 \%$ (0.16), and $11.69 \%$ $(0.18 \mathrm{mmol} / \mathrm{L})$ in the population with prediabetes; and $2.28 \%(0.12)$, $3.86 \%(0.12)$, and $29.87 \%(0.46 \mathrm{mmol} / \mathrm{L})$, respectively, in the population with diabetes, compared with those in the NGT population. In addition, HDL cholesterol level decreased by $2.60 \%(0.04)$ and $7.14 \%$ (or 0.11 $\mathrm{mmol} / \mathrm{L}$ ) in the populations with prediabetes and diabetes, compared with that in the NGT population. Thus, glucose metabolism disorder leads to the increase of the mean levels of serum total and LDL cholesterol and triglycerides, whereas the mean level of HDL cholesterol decreases. Additionally, glucose metabolism disorder greatly influences the triglyceride levels.

Several previous studies reported serum lipid and lipoprotein levels in Chinese population [16-19]. The China National Diabetes and Metabolic Disorders Study, which included 47,325 residents aged $\geq 20$ years around China, showed that the mean serum total, LDL, and HDL cholesterol and triglyceride levels were 4.72, 2.68, 1.30, and $1.57 \mathrm{mmol} / \mathrm{L}$, respectively [19]. In our study, which was only conducted $4-5$ years later, the total and LDL cholesterol and triglyceride levels increased by $13.35 \%(0.63)$, $18.66 \%(0.50)$, and $7.01 \%(0.11 \mathrm{mmol} / \mathrm{L})$, respectively. These increases are greatly evident and unlikely due to changes in laboratory measurement methods and different sampling methods. The serum lipid and lipoproteins are known to be closely related to age, and our study residents, which were aged $\geq 40$ years, and those in previous studies have different age range. These facts may be the reason behind the different results acquired between our study and previous studies. Nevertheless, this distinction could only lead to minimal difference. Therefore, the apparent increase in serum total and LDL cholesterol and triglyceride levels is most likely true. Furthermore, it will continue to increase if without effective intervention. 


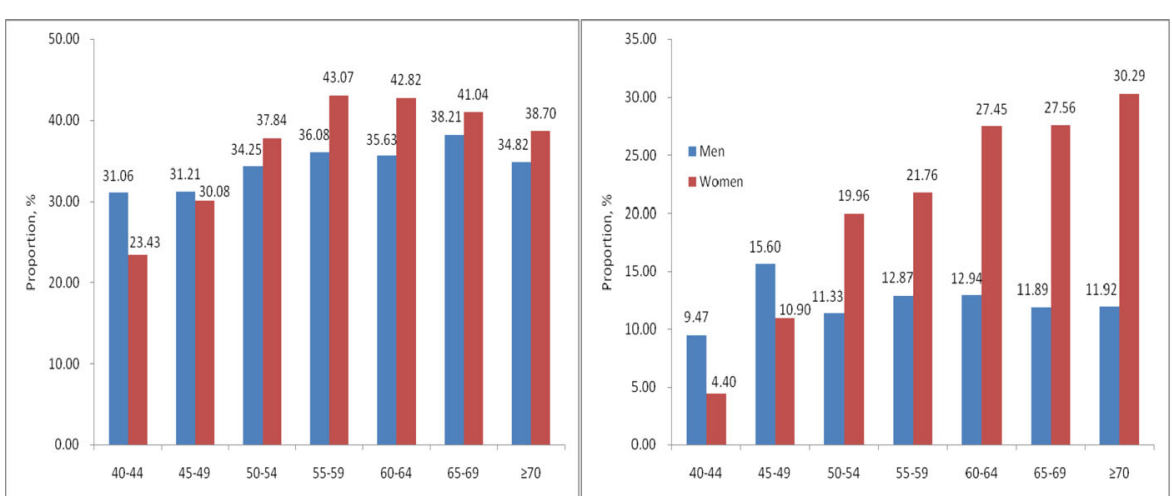

Age, years

Age, years

$P$-trend for age $<0.01$ in both men and women

$P$-trend for age $<0.01$ in both men and women Serum LDL cholesterol (3.37-4.13 mmol/L)

Serum LDL cholesterol $(\geq 4.14 \mathrm{mmol} / \mathrm{L})$

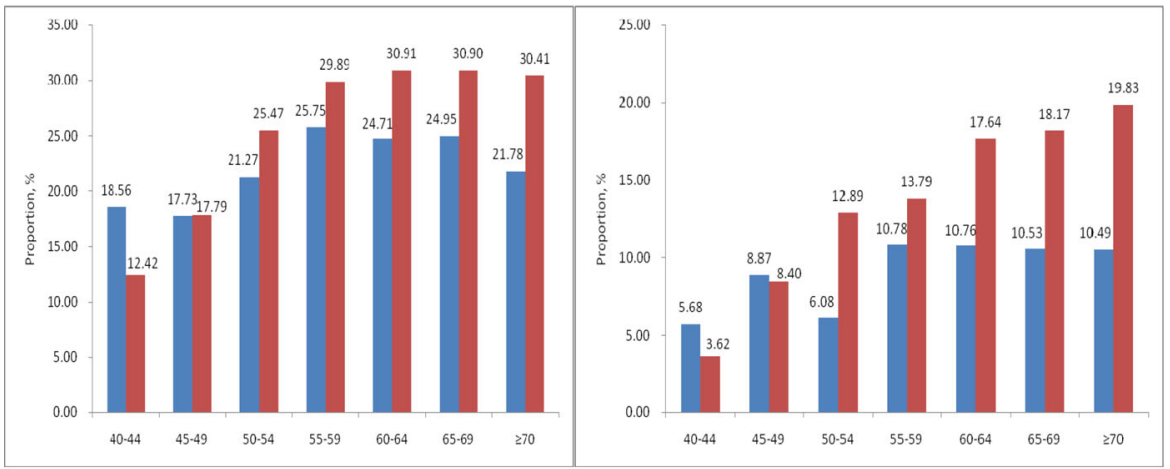

Age, years

Age, years

$P$-trend for age $<0.01$ in both men and women

$P$-trend for age $<0.01$ in both men and women Serum Triglycerides $(1.70-2.25 \mathrm{mmol} / \mathrm{L})$ Serum Triglycerides $(\geq 2.26 \mathrm{mmol} / \mathrm{L})$

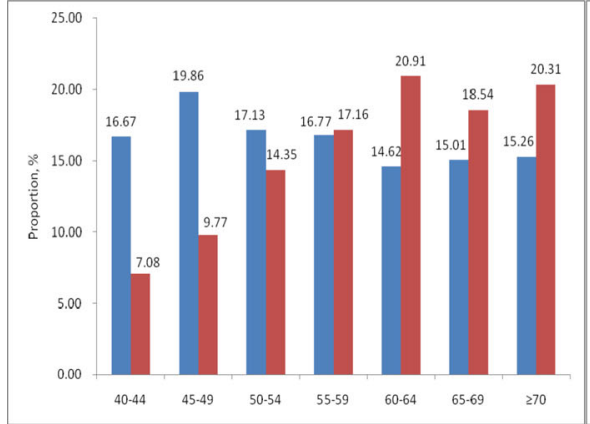

Age, years

$P$-trend for age $<0.01$ in both men and women

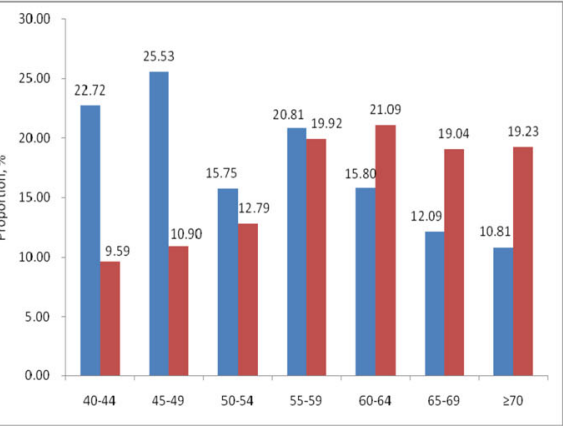

Age, years

$P$-trend for age $<0.01$ in both men and women

Fig. 1 Age-specific proportion of individuals with borderline-high and high total (top) and LDL (middle) cholesterol, as well as borderline-high and high serum triglycerides (bottom), among adults aged $\geq 40$ years in Shandong Province, 2012

These study results have immensely important public health implications. Traditionally, the mortality from atherosclerotic cardiovascular diseases has been uncommon in China and is estimated to be approximately one tenth of that in Western countries [20-23]. In our study, only $3 \%$ of the residents with dyslipidemia used lipid-lowering medication regularly. Without a national effective prevention and control of hypercholesterolemia, cardiovascular and cerebrovascular disease cases will continue to grow in China. However, contrary to the current situation in China [24-28], the serum cholesterol level in most countries worldwide has decreased remarkably over the past few decades [29-32]. 


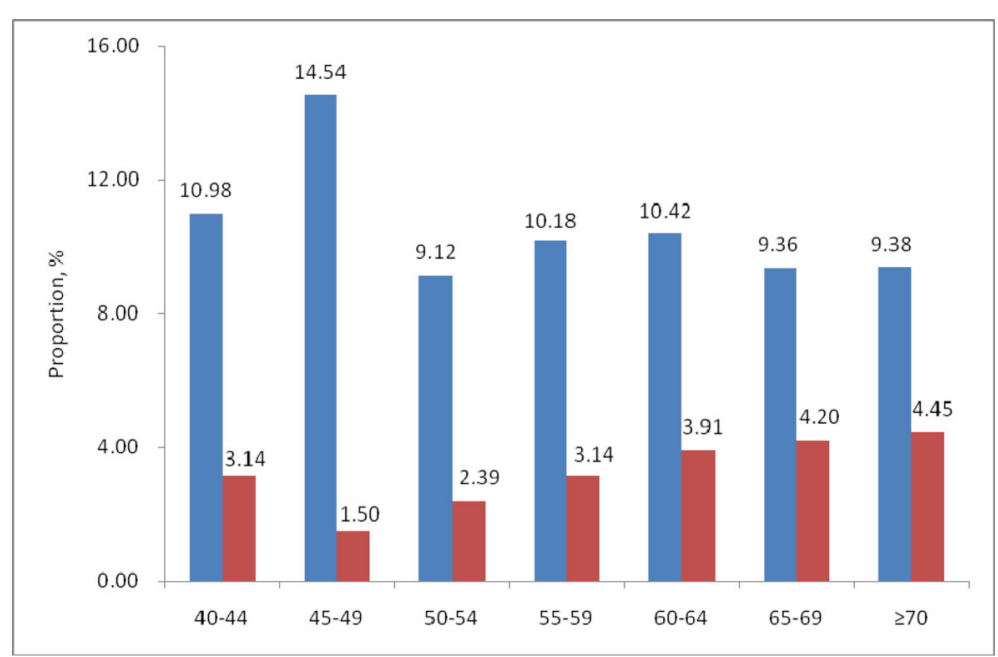

\section{$P$-trend for age $<0.01$ in both men and women}

Fig. 2 Age-specific proportion of individuals with lower serum HDL cholesterol among adults aged $\geq 40$ years in Shandong Province, 2012

Table 4 The Correlation of Total, LDL, and HDL Cholesterol and Triglycerides with Other Clinical Characteristics

\begin{tabular}{|c|c|c|c|c|}
\hline & \multicolumn{2}{|c|}{ Simple linear regression } & \multicolumn{2}{|c|}{ Multiple linear regression } \\
\hline & $\bar{r}$ & $P$ & $\bar{\beta}$ & $P$ \\
\hline \multicolumn{5}{|l|}{ Serum total cholesterol, $\mathrm{mmol} / \mathrm{L}$} \\
\hline Age, y & 0.165 & $<0.001$ & 0.169 & $<0.001$ \\
\hline Gender & 0.14 & $<0.001$ & 0.163 & $<0.001$ \\
\hline Status of glucose metabolism & 0.074 & $<0.001$ & 0.017 & 0.176 \\
\hline $\mathrm{BMI}, \mathrm{kg} / \mathrm{m}^{2}$ & 0.042 & $<0.001$ & 0.029 & 0.005 \\
\hline $\mathrm{HbA} 1 \mathrm{c}, \%$ & 0.082 & $<0.001$ & 0.045 & $<0.001$ \\
\hline \multicolumn{5}{|l|}{ Serum Triglycerides, mmol/L } \\
\hline Age, y & 0.022 & 0.03 & -0.018 & 0.091 \\
\hline Gender & -0.022 & 0.026 & -0.006 & 0.553 \\
\hline Status of glucose metabolism & 0.125 & $<0.001$ & 0.02 & 0.104 \\
\hline $\mathrm{BMI}, \mathrm{kg} / \mathrm{m}^{2}$ & 0.138 & $<0.001$ & 0.115 & $<0.001$ \\
\hline $\mathrm{HbA} 1 \mathrm{c}, \%$ & 0.204 & $<0.001$ & 0.171 & $<0.001$ \\
\hline \multicolumn{5}{|l|}{ Serum LDL cholesterol, mmol/L } \\
\hline Age, y & 0.168 & $<0.001$ & 0.158 & $<0.001$ \\
\hline Gender & 0.086 & $<0.001$ & 0.11 & $<0.001$ \\
\hline Status of glucose metabolism & 0.083 & $<0.001$ & -0.042 & 0.001 \\
\hline $\mathrm{BMI}, \mathrm{kg} / \mathrm{m}^{2}$ & 0.087 & $<0.001$ & 0.066 & $<0.001$ \\
\hline $\mathrm{HbA} 1 \mathrm{c}, \%$ & 0.163 & $<0.001$ & 0.154 & $<0.001$ \\
\hline \multicolumn{5}{|l|}{ Serum HDL cholesterol, mmol/L } \\
\hline Age, y & -0.067 & $<0.001$ & -0.02 & 0.055 \\
\hline Gender & 0.176 & $<0.001$ & 0.159 & $<0.001$ \\
\hline Status of glucose metabolism & -0.122 & $<0.001$ & -0.102 & $<0.001$ \\
\hline $\mathrm{BMI}, \mathrm{kg} / \mathrm{m}^{2}$ & -0.257 & $<0.001$ & -0.24 & $<0.001$ \\
\hline $\mathrm{HbA} 1 \mathrm{c}, \%$ & -0.055 & $<0.001$ & 0.044 & $<0.001$ \\
\hline
\end{tabular}


The present study has some limitations. First, our study was conducted in Shandong Province; therefore, the estimated results could not be applied to the entire Chinese population. Shandong Province is one of the Chinese coastal provinces and has a higher level of economic development, which possibly explains the higher increase in the mean levels of serum lipids and lipoproteins in Shandong Province adults than that in the entire Chinese population. Second, the gender distribution is imbalanced. Females were overrepresented.

\section{Conclusion}

Serum total and LDL cholesterol levels were high in the population aged $\geq 40$ years of Shandong province. Age, gender, status of glucose metabolism, BMI, and HbA1c can affect serum lipids and lipoproteins. Without effective prevention and intervention, cardiovascular and cerebrovascular disease cases will continue to grow in the future in China.

\begin{abstract}
Abbreviations
ALT: Alanine aminotransferase; AST: Aspartate aminotransferase; BMl: Body mass index; Cr: Creatinine; FINS: Fasting plasma insulin; FPG: Fasting plasma glucose; HbA1c: Glycosylated hemoglobin; HDL: High-density lipoprotein; HOMA-IR: Homeostasis model assessment insulin resistance; IFG: Impaired fasting glucose; IGT: Impaired glucose tolerance; LDL: Low-density lipoprotein; NGT: Normal glucose tolerance; WHR: Waist-hip ratio
\end{abstract}

\section{Acknowledgments}

We thank all the staff involved in this research for their kind support and discussion.

\section{Funding}

This study was supported by the grants from the National Key R\&D Program of China (No.2016YFC0901200) and the National Natural Science Foundation of China (NO.81670706)

\section{Availability of data and materials}

Our work was one part of the baseline survey from the REACTION study that investigated the association of diabetes and cancer, conducted among 259,657 adults aged $\geq 40$ years in 25 communities across mainland China, from 2011 to 2012 [8-11]. The datasets generated or analysed during this study are not publicly available due [REASON WHY DATA ARE NOT PUBLIC] but are available from the corresponding author on reasonable request.

\section{Authors' contributions}

MW: acquisition and analysis of data; interpretation of results and drafting the manuscript. XH, WH: participated in the study and analyzed the data. LC, SC: study supervision and critical revision. All authors read and approved the final manuscript.

\section{Ethics approval and consent to participate}

The ethics committee of Qilu Hospital of Shandong University approved the study. Written informed consent was obtained from each participant before data collection.

\section{Consent for publication}

Not applicable.

\section{Competing interests}

The authors declare that they have no competing interest.

\section{Publisher's Note}

Springer Nature remains neutral with regard to jurisdictional claims in published maps and institutional affiliations.

\section{Author details}

'Department of Endocrinology, Qilu Hospital of Shandong University (Qingdao), 758 Hefei Road, Qingdao, Shandong 266035, People's Republic of China. ${ }^{2}$ Department of Endocrinology of Qilu Hospital and Institute of Endocrinology and Metabolism, Qilu Hospital of Shandong University, 107 Wenhuaxi Road, Ji'nan, Shandong 250012, People's Republic of China. ${ }^{3}$ Department of Endocrinology, The Second Hospital of Shandong University, 247 Beiyuan Street, Ji'nan, Shandong 250033, People's Republic of China.

Received: 9 July 2018 Accepted: 26 February 2019

Published online: 04 March 2019

\section{References}

1. Zhai F, Wang H, Du S, He Y, Wang Z, Ge K, Popkin BM. Prospective study on nutrition transition in China. Nutr Rev. 2009;67(suppl 1):S56-61.

2. He J, Gu D, Wu X, Reynolds K, Duan X, Yao C, Wang J, Chen CS, ChenJ WRP, Klag MJ, Whelton PK. Major causes of death among men and women in China. N Engl J Med. 2005;353:1124-34.

3. Stamler J, Daviglus ML, Garside DB, Dyer AR, Greenland P, Neaton JD. Relationship of baseline serum cholesterol levels in 3 large cohorts of younger men to long-term coronary, cardiovascular, and all-cause mortality and to longevity. JAMA. 2000;284:311-8.

4. LaRosa JC, He J, Vupputuri S. Effect of statins on risk of coronary disease: a meta-analysis of randomized controlled trials. JAMA. 1999;282:2340-6.

5. Marcus AO. Lipid disorders in patients with type 2 diabetes. Meeting the challenges of early, aggressive treatment. Postgrad Med. 2001;110(1):111-23.

6. Chen Z, Peto R, Collins R, MacMahon S, Lu J, Li W. Serum cholesterol concentration and coronary heart disease in population with low cholesterol concentrations. BMJ. 1991;303:276-82.

7. Eastern Stroke and Coronary Heart Disease Collaborative Research Group. Blood pressure, cholesterol, and stroke in eastern Asia. Lancet. 1998;352:1801-7.

8. Ning G, Guang N, Shanghai J, et al. Risk evaluation of cAncers in Chinese diabeTic individuals: a IONgitudinal (REACTION) study. J Diabetes. 2012;4(2):172-3.

9. Bi Y, Lu J, Wang W, et al. Cohort profile: risk evaluation of cancers in Chinese diabetic individuals: a longitudinal (REACTION) study. J Diabetes. 2014;6(2):147-57.

10. Lu J, Bi Y, Wang T, et al. The relationship between insulin-sensitive obesity and cardiovascular diseases in a Chinese population: results of the REACTION study. Int J Cardiol. 2014;172(2):388-94.

11. Ning G, Bloomgarden Z. Diabetes and cancer: findings from the REACTION study. J Diabetes. 2015;7(2):143-4.

12. Luepkar RV, Evans A, McKeigue P, Reddy KS. Cardiovascular survey methods. 3rd ed. Geneva: World Health Organization; 2002.

13. Expert Panel on Detection, Evaluation, and Treatment of High Blood Cholesterol in Adults. Executive summary of the third report of the National Cholesterol Education Program (NCEP) expert panel on detection, evaluation, and treatment of high blood cholesterol in adults (adult treatment panel III). JAMA. 2001;285:2486-2496.

14. American Diabetes Association. Standards of medical care in diabetes-2015 abridged for primary care provides. Clin Diabetes. 2015;33(2):97-111.

15. People's Republic of China-United States Cardiovascular and Cardiopulmonary Epidemiology Research Group. An epidemiological study of cardiovascular and cardiopulmonary disease risk factors in four populations in the People's republic of China: baseline report from the P.R. C.-U.S.a. collaborative study. Circulation. 1992;85:1083-96.

16. Li YH, Li Y, Davis CE, Chen Z, Tao S, Folsom AR, Bachorik P, Stamler J, Abernathy JR. Serum cholesterol changes from 1983-1984 to 1993-1994 in the People's Republic of China. Nutr Metab Cardiovasc Dis. 2002;12(3):118-26.

17. He J, Gu D, Reynolds K, Wu X, Muntner P, Zhao J, Chen J, Liu D, Mo J, Whelton PK. InterASIA collaborative group. Serum total and lipoprotein cholesterol levels and awareness, treatment, and control of hypercholesterolemia in China. Circulation. 2004;110:405-11.

18. Zhang B, Zhai FY, Du SF, Popkin BM. The China health and nutrition survey, 1989-2011. Obes Rev. 2014 Jan;15(Suppl 1):2-7.

19. Wengying $Y$, Jianzhong $X$, Zhaojun $Y$, Linong J, Weiping J. Etc. serum lipids and lipoproteins in Chinese men and women. Circulation. 2012;125:2212-21.

20. Tao SC, Huang ZD, Wu XG, Zhou BF, Xiao ZK, Hao JS, Li YH, Cen RC, Rao XX. CHD and its risk factors in the People's republic of China. Int J Epidemiol. 1989;18:5159-63. 
21. Hu D. Some thoughts on the prevention and control of dyslipidemia and atherosclerotic cardiovascular disease in China. Zhonghua Nei Ke Za Zhi. 2014;53(4):257-8.

22. Liu CY, Chen CQ. Intra- and extracranial atherosclerotic stenosis in China: epidemiology, diagnosis. treatment and risk factors Eur Rev Med Pharmacol Sci. 2014;18(22):3368-79.

23. Celermajer DS, Chow CK, et al. Cardiovascular disease in the developing world: prevalences, patterns, and the potential of early disease detection. J Am Coll Cardiol. 2012;60(14):1207-16.

24. S M, Nagai A, et al. Serum lipid fractions and cerebral microbleeds in a healthy Japanese population. Cerebrovasc Dis. 2017:43(3-4):186-91.

25. Liu X, Yu S, et al. Dyslipidemia prevalence, awareness, treatment, control, and risk factors in Chinese rural population: the Henan rural cohort study. Lipids Health Dis. 2018;17(1):119.

26. Zhang M, Zhou J, et al. Risk of type 2 diabetes mellitus associated with plasma lipid levels: the rural Chinese cohort study. Diabetes Res Clin Pract. 2018:135:150-7.

27. $\mathrm{SH}, \mathrm{Xu}$ Y, et al. Serum apolipoprotein E concentration and polymorphism influence serum lipid levels in Chinese Shandong Han population. Medicine (Baltimore). 2016;95(50):e5639.

28. Lv $H$, Yang $X$, et al. Parity and serum lipid levels: a cross-sectional study in chinese female adults. Sci Rep. 2016;6:33831.

29. Farzadfar F, Finucane MM, Danaei G, et al. National, regional, and global trends in serum total cholesterol since 1980: systematic analysis of health examination surveys and epidemiological studies with 321 country-years and 3.0 million participants. Lancet. 2011:377(9765):578-86.

30. Evans A, Tolonen $\mathrm{H}$, Hense HW, et al. Trends in coronary risk factors in the WHO MONICA project. Int J Epidemiol. 2001;30(suppl 1):35-40.

31. Carroll MD, Lacher DA, Sorlie PD, et al. Trends in serum lipids and lipoproteins of adults, 1960-2002. JAMA. 2005;294(14):1773-81.

32. Kuklina EV, Yoon PW, Keenan NL. Trends in high levels of low-density lipoprotein cholesterol in the United States, 1999-2006. JAMA. 2009:302(19):2104-10.

Ready to submit your research? Choose BMC and benefit from:

- fast, convenient online submission

- thorough peer review by experienced researchers in your field

- rapid publication on acceptance

- support for research data, including large and complex data types

- gold Open Access which fosters wider collaboration and increased citations

- maximum visibility for your research: over $100 \mathrm{M}$ website views per year

At $\mathrm{BMC}$, research is always in progress.

Learn more biomedcentral.com/submissions 